\title{
ИССЛЕДОВАНИЕ СВЯЗИ МЕЖДУ ИНДЕКСАМИ УДЕРЖИВАНИЯ И ТЕМПЕРАТУРАМИ КИПЕНИЯ $\boldsymbol{н}$-АЛКЕНОВ И $\boldsymbol{w}$-АЛКИНОВ
}

В статье рассматриваются корреляции между температурами кипения $t_{\text {кип }}$ и индексами удерживания $I \boldsymbol{H}$-алканов, $\boldsymbol{H}$-алкенов и $\boldsymbol{H}$-алкинов $\mathrm{C}_{6}-\mathrm{C}_{11}$, измеренными на графитированной термической саже. Необходимые для расчетов величины $I$ при $175^{\circ} \mathrm{C}$ получены по данным ['], температуры кипения взяты из $\left[{ }^{2-4}\right]$.

Значения $I^{175^{\circ}}$ для гомологических рядов изученных $H$-алкенов и н-алкинов скоррелированы с температурами кипения изомеров по следующим уравнениям:

$$
\begin{aligned}
& t_{\text {Кй }}=a+b I^{175^{\circ}}, \\
& t_{\text {Кй }}=a^{\prime}+b^{\prime} I^{175^{\circ}}+c^{\prime}\left(I^{175^{\circ}}\right)^{2}, \\
& t_{\text {Кй }}=a^{\prime \prime}+\frac{b^{\prime \prime}}{c^{\prime \prime}+I^{175^{\circ}}} .
\end{aligned}
$$

Коэффициенты уравнений (1)-(3) определены методом наименьших квадратов на ЭВМ ЕС 1022 и для уравнений (2) и (3) приведены в табл. 1 и 2.

Надежность корреляции и практическая ценность уравнений охе рактеризованы:

1) доверительным интервалом $\varepsilon_{0,95}=s \cdot t_{0,95}$, где $t_{0,95}-$ распределение Стьюдента при $P=0,95, s$ - стандартные погрешности коэффициентов $a, b$ и $c$;

2) коэффициентом множественной корреляции $R_{0}$;

Таблица 1

Коэффициенты уравнения (2) и характеристика корреляции

\begin{tabular}{l|c|c|c|c|c|c|c}
\hline \begin{tabular}{c} 
Гомологические \\
\multicolumn{1}{c|}{ ряды }
\end{tabular} & $a^{\prime} \pm \varepsilon$ & $b^{\prime} \pm \varepsilon$ & $\left(c^{\prime} \pm \varepsilon\right) \cdot 10^{5}$ & $n$ & $R_{0}$ & $s_{0}$ & $\begin{array}{c}s_{0} / \\
\Delta t_{\mathrm{1ни}}\end{array}$ \\
\hline & & & & & & \\
н-Алканы & $129,42 \pm 2,33$ & $0,40921 \pm 0,03140$ & $-9,137 \pm 1,83$ & 6 & 0,99998 & 0,405 & 0,003 \\
-1-Алкены & $129,40 \pm 1,89$ & $0,41268 \pm 0,02483$ & $-9,309 \pm 1,47$ & 6 & 0,99999 & 0,329 & 0,003 \\
цис-2-Алкены & $133,68 \pm 2,20$ & $0,42505 \pm 0,02834$ & $-10,45 \pm 1,69$ & 6 & 0,99998 & 0,382 & 0,003 \\
транс-2-Алкены & $121,86 \pm 4,94$ & $0,43577 \pm 0,06728$ & $-10,76 \pm 3,99$ & 6 & 0,99990 & 0,859 & 0,007 \\
цис-3-Алкены & $128,57 \pm 1,81$ & $0,43653 \pm 0,02360$ & $-11,11 \pm 1,44$ & 6 & 0,99999 & 0,315 & 0,003 \\
транс-3-Алкены & $132,58 \pm 4,38$ & $0,41597 \pm 0,05957$ & $-9,686 \pm 3,6$ & 6 & 0,99992 & 0,762 & 0,006 \\
цис-4-Алкены & $119,01 \pm 6,27$ & $0,46398 \pm 0,13195$ & $-12,74 \pm 7,27$ & 4 & 0,99998 & 0,341 & 0,005 \\
транс-4-Алкены & $130,35 \pm 9,93$ & $0,41781 \pm 0,22354$ & $-9,736 \pm 12,09$ & 4 & 0,99995 & 0,539 & 0,008 \\
1-Алкины & $142,54 \pm 4,38$ & $0,41792 \pm 0,05827$ & $-10,388 \pm 3,58$ & 6 & 0,99992 & 0,762 & 0,006 \\
2-Алкины & $165,68 \pm 4,63$ & $0,39050 \pm 0,07605$ & $-9,138 \pm 4,93$ & 5 & 0,99995 & 0,566 & 0,006 \\
3-Алкины & $172,16 \pm 9,25$ & $0,37718 \pm 0,15261$ & $-8,43 \pm 10,18$ & 5 & 0,99979 & 1,132 & 0,012 \\
4-Алкины & $156,38 \pm 28,45$ & $0,42064 \pm 0,9308$ & $-11,29 \pm 55,65$ & 3 & 0,99994 & 0,350 & 0,008
\end{tabular}


3) среднеквадратичным отклонением $s_{0}$ экспериментальных значений от вычисленных (стандартная ошибка корреляции)

$$
s_{0}=\left[\sum_{j=1}^{n}\left(t_{j}^{\text {расч }}-t_{j}^{\text {эксп }}\right)^{2} /(n-m)\right]^{1 / 2},
$$

где $n$ - число экспериментальных точек, $m$ - число констант уравнения, равных в данном случае 2 и 3 ;

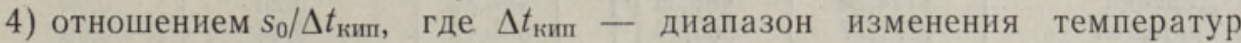
кипения.

Различия между литературными и рассчитанными по уравнению

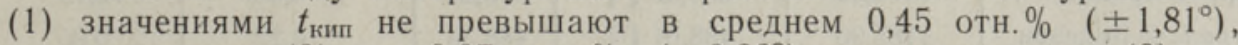
по уравнению $(2)-0,07$ отн. $\%\left( \pm 0,28^{\circ}\right)$, по уравнению (3) 0,07 отн. \% $\left( \pm 0,27^{\circ}\right)$. Результаты показывают, что уравнение типа (3), как дающее наилучшую корреляцию между $t_{\text {ки }}$ и $I^{175^{\circ}}$, может быть использовано для предсказаңия температур кипения высших гомологов.

Зависимости экспериментальных данных по $I$ от числа атомов углерода $n_{\mathrm{C}}$ в молекуле олефина лучше всего выражаются уравнением типа

$$
I^{175^{\circ}}=a_{1}+b_{1} n_{\mathrm{C}}+c_{1} n_{\mathrm{C}}^{2} .
$$

Таблица 2

Коэффициенты уравнения (3)

\begin{tabular}{l|c|r|r|r|r|r|r|r|c}
\hline \begin{tabular}{l} 
Гомологические \\
\multicolumn{1}{c}{ ряды }
\end{tabular} & $n$ & $a^{\prime \prime}$ & $\begin{array}{l}-b^{\prime \prime} \\
\cdot 10^{-2}\end{array}$ & $c^{\prime \prime}$ & $s_{0}$ & $a_{1}^{\prime \prime}$ & $\begin{array}{r}-b_{1}^{\prime \prime} \\
10^{-2}\end{array}$ & $c_{1}^{\prime \prime}$ & $s_{0}$ \\
\hline н-Алканы & 6 & 1119,5 & 19889 & 1957,9 & 0,433 & & & & \\
н-1-Алкены & 6 & 1127,1 & 20174 & 1974,5 & 0,397 & 1117,7 & 19653 & 1938,4 & 0,042 \\
цис-2-Алкены & 6 & 1026,4 & 15021 & 1624,4 & 0,344 & 1018,9 & 14648 & 1593,6 & 0,067 \\
транс-2-Алкены & 6 & 1024,4 & 14839 & 1582,7 & 0,713 & 1019,7 & 14609 & 1563,7 & 0,204 \\
цис-3-Алкены & 6 & 998,1 & 13640 & 1506,6 & 0,302 & 991,52 & 13340 & 1481,2 & 0,118 \\
транс-3-Алкены & 6 & 1100,7 & 18764 & 1890,6 & 0,726 & 1092,7 & 18329 & 1859,0 & 0,280 \\
цис-4-Алкены & 4 & 873,6 & 8308 & 987,3 & 0,393 & 860,42 & 7819,3 & 931,16 & 0,02 \\
транс-4-Алкены & 4 & 1070,1 & 17098 & 1760,7 & 0,745 & 1028,7 & 14950 & 1586,8 & 0,285 \\
& 6 & 1015,6 & 14675 & 1624,9 & 0,564 & 1016,2 & 14708 & 1627,5 & 0,074 \\
1-Алкины & 5 & 1108,0 & 19470 & 2028,1 & 0,512 & 1070,5 & 17461 & 1882,6 & 0,545 \\
2-Алкины & 5 & 1229,6 & 27046 & 2539,5 & 1,147 & 1065,0 & 17370 & 1892,7 & 0,567 \\
3-Алкины & 3 & 903,98 & 9744,5 & 1216,1 & 0,014 & 1013,3 & 14724 & 1683,8 & 0,003 \\
4-Алкины &
\end{tabular}

таблица 3

Коэффйциенты уравнения (4) и характеристика корреляции

\begin{tabular}{l|c|c|c|c|c|c}
\hline $\begin{array}{c}\text { Гомологические } \\
\text { ряды }\end{array}$ & $a_{1}$ & $b_{1}$ & $c_{1}$ & $R_{0}$ & $n$ & $s_{0}$ \\
\hline & & & & & \\
н-Алканы & $-0,03735$ & 100,01 & $-0,000537$ & 1,00000 & 6 & 0 \\
н-1-Алкены & $-38,183$ & 104,32 & $-0,27347$ & 0,99997 & 6 & 1,7559 \\
цис-2-Алкены & $-9,8411$ & 94,967 & 0,29526 & 0,99998 & 6 & 1,5138 \\
транс-2-Алкены & 7,7576 & 95,678 & 0,20835 & 0,99996 & 6 & 2,1457 \\
цис-3-Алкены & 18,267 & 86,939 & 0,70363 & 0,99998 & 6 & 1,4216 \\
транс-3-Алкены & $-8,3223$ & 97,003 & 0,076397 & 0,99996 & 6 & 2,1794 \\
цис-4-Алкены & 160,06 & 55,220 & 2,3378 & 1,0001 & 4 & 3,0143 \\
транс-4-Алкены & 20,591 & 91,100 & 0,39216 & 0,99994 & 4 & 2,3460 \\
1-Алкины & 1,8042 & 90,307 & 0,51015 & 0,99996 & 6 & 2,1262 \\
2-Алкины & $-31,130$ & 99,877 & $-0,057057$ & 0,99989 & 6 & 3,5649 \\
3-Алкины & 6,9812 & 86,703 & 0,66484 & 0,99996 & 6 & 2,0666 \\
4-Алкины & 4,9194 & 85,235 & 0,75090 & 1,0001 & 4 & 2,2465
\end{tabular}


Сравнение рассчитанных по уравнению (3) значений нормальных температур кипения изомеров $\boldsymbol{\mu}$-алкенов и $\boldsymbol{н}$-алкинов $\mathrm{C}_{12}-\mathrm{C}_{13}$ с литературными данными

\begin{tabular}{|c|c|c|c|c|c|}
\hline \multirow[b]{2}{*}{ Изомеры } & \multirow[b]{2}{*}{$I_{\mathrm{pacu}}^{175^{\circ}}$} & \multirow{2}{*}{$\begin{array}{c}t_{\text {кли }} \\
\text { (лит. данные) }\end{array}$} & \multicolumn{3}{|c|}{ Расчет } \\
\hline & & & yp. (3) & $\begin{array}{c}\Delta t_{\mathrm{KIn}}= \\
=t_{\mathrm{II \tau}}-t_{\mathrm{pacq}}\end{array}$ & $\frac{\Delta t_{\text {кип }}}{t_{\text {лит }}}, \%$ \\
\hline $\begin{array}{l}\text { 1-Додецен } \\
\text { 1-Тридецен }\end{array}$ & $\begin{array}{l}1174,28 \\
1271,77\end{array}$ & $\begin{array}{l}486,52\left[{ }^{3}\right] \\
505,93\left[{ }^{2}\right]\end{array}$ & $\begin{array}{l}486,32 \\
505,49\end{array}$ & $\begin{array}{l}0,20 \\
0,44\end{array}$ & $\begin{array}{l}0,04 \\
0,09\end{array}$ \\
\hline $\begin{array}{l}\text { цис-2-Додецен } \\
\text { цис-2-Тридецен }\end{array}$ & $\begin{array}{l}1172,28 \\
1274,63\end{array}$ & $\begin{array}{l}489,62\left[{ }^{3}\right] \\
508,83\left[{ }^{4}\right]\end{array}$ & $\begin{array}{l}489,30 \\
508,20\end{array}$ & $\begin{array}{l}0,32 \\
0,63\end{array}$ & $\begin{array}{l}0,07 \\
0,12\end{array}$ \\
\hline $\begin{array}{l}\text { транс-2-Додецен } \\
\text { транс-2-Тридецен }\end{array}$ & $\begin{array}{l}1185,90 \\
1286,78\end{array}$ & $\begin{array}{l}488,61\left[^{3}\right] \\
507,86\left[{ }^{4}\right]\end{array}$ & $\begin{array}{l}488,39 \\
507,19\end{array}$ & $\begin{array}{l}0,22 \\
0,67\end{array}$ & $\begin{array}{l}0,05 \\
0,13\end{array}$ \\
\hline $\begin{array}{l}\text { цис-3-Додецен } \\
\text { цис-3-Тридецен }\end{array}$ & $\begin{array}{l}1162,86 \\
1267,39\end{array}$ & $\begin{array}{l}487,00\left[{ }^{3}\right] \\
506,12\left[{ }^{4}\right]\end{array}$ & $\begin{array}{l}486,99 \\
506,18\end{array}$ & $\begin{array}{r}0,01 \\
-0,06\end{array}$ & $\begin{array}{l}0,002 \\
0,01\end{array}$ \\
\hline $\begin{array}{l}\text { транс-3-Додецен } \\
\text { транс-3-Тридецен }\end{array}$ & $\begin{array}{l}1166,71 \\
1265,63\end{array}$ & $\begin{array}{l}487,15\left[{ }^{4}\right] \\
506,34\left[{ }^{4}\right]\end{array}$ & $\begin{array}{l}486,93 \\
506,10\end{array}$ & $\begin{array}{l}0,22 \\
0,24\end{array}$ & $\begin{array}{l}0,045 \\
0,047\end{array}$ \\
\hline $\begin{array}{l}\text { цис-4-Додецен } \\
\text { цис-4-Тридецен } \\
\text { транс-4-Додецен } \\
\text { транс-4-Тридецен }\end{array}$ & $\begin{array}{l}1159,34 \\
1273,01 \\
1170,26 \\
1271,17\end{array}$ & $\begin{array}{l}486,34\left[{ }^{4}\right] \\
505,54\left[{ }^{4}\right] \\
486,40\left[{ }^{3}\right] \\
505,83\left[{ }^{4}\right]\end{array}$ & $\begin{array}{l}486,38 \\
505,67 \\
486,46 \\
505,60\end{array}$ & $\begin{array}{r}-0,04 \\
-0,13 \\
-0,06 \\
0,23\end{array}$ & $\begin{array}{c}0,008 \\
0,026 \\
-0,01 \\
0,05\end{array}$ \\
\hline 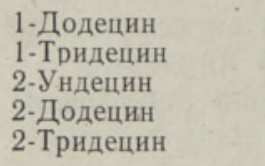 & $\begin{array}{l}1158,95 \\
1262,01 \\
1060,61 \\
1159,18 \\
1257,63\end{array}$ & $\begin{array}{l}488,28\left[{ }^{4}\right] \\
506,97\left[{ }^{4}\right] \\
477,06\left[{ }^{4}\right] \\
496,19\left[^{4}\right] \\
514,15\left[{ }^{4}\right]\end{array}$ & $\begin{array}{l}488,36 \\
507,19 \\
477,21 \\
496,46 \\
514,46\end{array}$ & $\begin{array}{r}-0,08 \\
-0,22 \\
-0,15 \\
-0,27 \\
-0,31\end{array}$ & $\begin{array}{l}-0,02 \\
-0,04 \\
-0,03 \\
-0,05 \\
-0,06\end{array}$ \\
\hline
\end{tabular}

Применение коэффициентов этого уравнения для гомологических рядов (табл. 3) показало, что различия между расчетными и экспериментальными величинами $I$ в среднем не превышают 0,12 отн. $\%$ ( $\pm 0,95$ ед. $I)$. Использовав вычисленные по уравнению (4) величины $I_{\text {расч }}^{175^{\circ}}$ для кор-

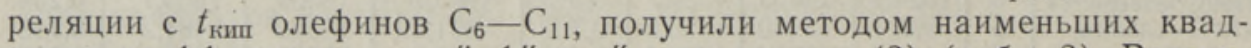
ратов коэффициенты $a_{1}^{\prime \prime}, b_{1}^{\prime \prime}$ и $c_{1}^{\prime \prime}$ уравнения (3) (табл. 2). Рассчитанные по ним $t_{\text {кшा }}$ отличаются от литературных данных $\left[{ }^{3-6}\right]$ не более чем на 0,03 отн. $\%\left( \pm 0,12^{\circ}\right)$ для олефинов $\mathrm{C}_{6}-\mathrm{C}_{11}$, и не более чем на 0,05 отн. $\%\left( \pm 0,24^{\circ}\right)$ для олефинов $\mathrm{C}_{12}-\mathrm{C}_{13}$ (табл. 4$)$.

\section{Выводы}

Установлено, что зависимость нндексов удерживания $н$-алкенов и $H$-алкинов $\mathrm{C}_{6}-\mathrm{C}_{11}$, измеренных на графитированной термической саже при температуре колонки $175^{\circ} \mathrm{C}$, от числа атомов углерода в молекуле олефина наиболее точно описывается уравнением полинома второй степени, а от температуры кипения олефина - уравнением типа Антуана. Приведены коэффициенты этих корреляционных уравнений, позволяющие рассчитывать индексы удерживания и температуры кипения высших гомологов.

\section{ЛИТЕРАТ У РА}

1. Пильт A., Ранг С., Эйзен О. Индексы удерживания н-алкенов и н-алкинов $\mathrm{C}_{6}-\mathrm{C}_{11}$ на графитированной термической саже. - Изв. АН ЭССР. Хим. Геол., 1972, 21, № $1,30-38$.

2. Физико-химические свойства индивидуальных углеводородов. Под ред. В. И. Татевского. М., 1960. 
3. Эльвельт A. A. Исследование физнко-химических свойств изомеров положения связи и конфигурации нормальных алкенов. Автореф. канд. дис. Тарту, 1977.

4. Kudrjawzewa, L., Elwelt, A., Kuus, M., Eisen, O. Zur zwischenmolekularen Wechselwirkung in $n$-Alkene und $n$-Alkine enthaltenden Mischungen. - Chem. Techn., 1982, 34, Heft 3, 136-139.

5. Эльвельт А., Отса Э., Эйзен О. Физико-химические характеристики изомерных н-октинов и н-нонинов. - Изв. АН ЭССР. Хим., 1979, 28, № 4, 287-289.

6. Эльвельт А., Эйзен $O$. О физико-химических характеристиках изомерных н-децинов. - Изв. АН ЭССР. Хим., 1978, 27, № 1, 54-56.

\author{
Институт химии \\ Академии наук Эстонской ССР
}

Поступила в редакцию 6/IV 1984

Aime MEISTER, Silvia _RANG, O. EISEN

\title{
n-ALKEENIDE JA n-ALKOONIDE RETENTSIOONIINDEKSITE NING KEEMISTEMPERATUURIDE VAHELISE SEOSE UURIMINE
}

On leitud, et kõige paremini korreleeruvad n-alkeenide ja n-alküünide $\mathrm{C}_{6}-\mathrm{C}_{11}$ isomeeride retentsiooniindeksid (mõödetud termiliselt grafiiditud tahmal kolonni temperatuuril $175{ }^{\circ} \mathrm{C}$ ) süsinikuaatomite arvuga olefiini molekulis teise astme polünoomvõrrandi järgi, aga keemistẻmperatuuridega Antoine’i võrrandi järgi. Toodud korrelatsioonivõrrandite koefitsiendid võimaldavad arvutada nende homoloogiliste ridade kõrgemate liikmete retentsiooniindekseid ja keemistemperatuure.

Aime MEISTER, Silvia RANG, O. EISEN

\section{INVESTIGATION OF THE RELATIONSHIP BETWEEN RETENTION INDICES AND BOILING POINTS OF n-ALKENES AND $n$-ALKYNES}

The retention indices of $\mathrm{C}_{6}-\mathrm{C}_{11} n$-alkenes and $n$-alkynes at the column temperature $175{ }^{\circ} \mathrm{C}$ on the graphitized thermal carbon black reveal the best correlation with the number of carbon atoms in the molecule by the second degree polynome, but with the boiling points of olefins by the Antoine type equation. The constants of equations calculated may be applied to establish retention indices and boiling points of higher isomers in these homologous series. 